\title{
Monitoring and Tracking Changes in Sensitivity to Azoxystrobin Fungicide in Alternaria solani in Wisconsin
}

\author{
N. Rosenzweig, Department of Plant Pathology, University of Wisconsin, Madison 53706; G. Olaya, Syngenta Crop \\ Protection Inc., Vero Beach Research Center, Vero Beach, FL 32967; Z. K. Atallah, Department of Plant Pathology, \\ University of Wisconsin, Madison; S. Cleere and C. Stanger, Syngenta Crop Protection Inc., Jealott's Hill Research \\ Station, Bracknell, Berkshire, RG42 6EY, UK; and W. R. Stevenson, Department of Plant Pathology, University of \\ Wisconsin, Madison
}

\begin{abstract}
Rosenzweig, N., Olaya, G., Atallah, Z. K., Cleere, S., Stanger, C., and Stevenson, W. R. 2008. Monitoring and tracking changes in sensitivity to azoxystrobin fungicide in Alternaria solani in Wisconsin. Plant Dis. 92:555-560.

Azoxystrobin is a common fungicide used by farmers of Solanaceous crops against Alternaria solani, but there was growing concern about decreased sensitivity with repeated applications. In 2002 and 2003, monitoring of A. solani from commercial potato fields in Wisconsin indicated increased frequency and a statewide distribution of isolates with decreased in vitro sensitivity to azoxystrobin. Mean effective concentration in inhibiting spore germination by $50 \%$ values gathered in 2002 and 2003 were approximately 20 -fold higher than baseline isolates of A. solani collected in 1998 from fields that had never been treated with azoxystrobin. This sensitivity decrease was correlated with site-specific mutations in the cytochrome $b$ detected by quantitative real-time polymerase chain reaction. The F129L and the G143A substitution have been shown to cause a reduction in sensitivity or resistance, respectively, to quinone outside inhibitors. All of the recovered A. solani isolates collected in 2002 and 2003 were wild type at position 143. However, all three mutations responsible for the F129L substitution (TTA, CTC, and TTG) were detected in our samples. In addition, the frequency of this amino acid substitution in A. solani isolates was statistically different across sampling sites and years, indicating that sensitivity changes depended on specific disease management practices.
\end{abstract}

Additional keywords: fungicide resistance, QoI, quantitative PCR

Early blight caused by Alternaria solani Sorauer is a seasonal concern for growers of Solanaceous crops and particularly for commercial potato and tomato growers. Foliar lesions associated with early blight lead to premature and progressive defoliation, which decreases plant photosynthetic capacity and, ultimately, reduces tuber yield $(15,20)$. Losses in commercial production potato fields can exceed $20 \%$, and losses as high as 70 to $80 \%$ have been reported in experimental field plots not treated with fungicides $(15,20)$. In the Midwestern United States, control of this polycyclic disease on potato cultivars depends primarily on multiple, typically weekly, fungicide applications. Although there currently are a wide variety of fungicides to choose from, the quinone outside inhibitors (QoIs) that include azoxystrobin are often favored because of their broad-based protection against distantly related fungi and oomycetes and

Corresponding author: N. Rosenzweig

E-mail: rosen660@umn.edu

Accepted for publication 6 August 2007.

doi:10.1094/PDIS-92-4-0555

(c) 2008 The American Phytopathological Society reduced deleterious environmental effects.

The mode of action of QoI fungicides disrupts mitochondrial respiration by chemically binding to the quinone outside site in the cytochrome $b$ complex. As a result of this narrow mode of action, there is an inherent risk for the evolution of pathogen resistance, which already has been widely reported for the QoI fungicides $(1-3,7,9,11,13)$. Reports of resistance to QoI fungicides were first described in isolates of Blumeria graminis f. sp. tritici, the cause of powdery mildew on wheat, collected from commercial fields in Europe after only 2 years of azoxystrobin use (16). Studies showed that product efficacy had declined compared with earlier disease control levels at many of these sites, and no differences in pathogenic fitness between QoI-resistant and -sensitive B. graminis isolates was detected $(3,22)$. The reason for this reduction was a single-point mutation in the DNA sequences of the cytochrome $b$ in QoIsensitive versus -resistant field isolates of several fungi $(1,2,7,10,13)$. Based on sequence alignments, an amino acid substitution from glycine $(\mathrm{G})$ to alanine $(\mathrm{A})$ corresponding to position 143 of the Saccharomyces cerevisiae cytochrome $b$ gene rendered M. fijiensis, B. graminis, Pyricu- laria grisea, Colletotrichum graminicola, Alternaria spp., Plasmopara viticola, and Venturia inaequalis resistant to QoIs $(1,2,7,10)$. Another amino acid substitution from phenylalanine $(\mathrm{F})$ to leucine $(\mathrm{L})$, corresponding to position 129 of the $S$. cerevisiae cytochrome $b$ gene, also was described for Pythium aphanidermatum, A. solani, Pyricularia grisea, and Plasmopara viticola with decreased sensitivity to QoIs $(2,8,11)$. The F129L substitution has been shown to cause a reduced sensitivity or tolerance to QoIs whereas the G143A substitution results in resistance or no response to QoIs.

An experimental use permit (EUP) was granted by the United States Environmental Protection Agency (EPA) that allowed potato growers in Wisconsin to use azoxystrobin (Quadris; Syngenta Crop Protection Inc., Greensboro, NC) for control of A. solani midseason in 1998. Since 1999, subsequent to label registration and widespread grower use, the level of early blight control in Wisconsin using azoxystrobin progressively declined in experimental field plots and efficacy had declined in some commercial growers' fields (17-19,24-28). Research on QoI resistance in A. solani conducted in other potato production regions highlighted the widespread distribution of isolates showing decreased sensitivity to azoxystrobin $(13,14)$. However, the frequency of different QoIresistant mutant individuals and the population biology of field populations of $A$. solani was not well documented in Wisconsin, which represents a major U.S. commercial potato production area.

Disease pressure and number of spray applications are both major factors influencing the evolution of fungicide resistance $(3,13,14,17-19,22)$. The persistent and intensive use of azoxystrobin (Quadris) and other QoI fungicides on commercially grown potato crops in Wisconsin and throughout the United States have increased the selective advantage of QoI-resistant mutants in A. solani populations. As a result, comprehensive monitoring to determine the frequency and distribution of $A$. solani isolates with reduced sensitivity to azoxystrobin is imperative in major production areas for continued effective use of this fungicide. The objectives of the study were to (i) determine 
whether a reduction in sensitivity to azoxystrobin in A. solani populations has occurred in Wisconsin between the baseline year of 1998 and years subsequent to the registration and widespread use of azoxystrobin, (ii) correlate observed reductions in sensitivity with site-specific mutations in the cytochrome $b$ gene caused by singlenucleotide polymorphisms (SNPs), (iii) compare sensitivity and SNP frequency in terms of local and regional differences in use patterns, and (iv) determine whether azoxystrobin sensitivity in A. solani differs between SNP mutant types.

\section{MATERIALS AND METHODS}

General approach. A. solani isolates were recovered from potato leaves collected from commercial growers' fields representing major production regions throughout Wisconsin. Sensitivity of $A$. solani isolates to azoxystrobin was determined using an in vitro assay based on germination of conidia on azoxystrobin-amended agar relative to nonamended agar. Quantitative real-time polymerase chain reaction (Q-PCR) assays were employed to evaluate whether shifts in sensitivity to azoxystrobin were correlated with site-specific mutations in the cytochrome $b$ gene.

Materials. Technical-grade azoxystrobin (95.3\% active ingredient) was obtained from Syngenta Crop Protection. Bacto Agar was from Difco Laboratories (Detroit). All other chemicals and materials were from Fisher Scientific (Chicago) or Aldrich (Milwaukee, WI) unless otherwise noted.

Sampling procedure and maintenance of A. solani isolates. In 1998, Quadris Flowable fungicide was applied to approximately 800 ha in 27 fields in Wisconsin. As part of the EPA-EUP agreement with growers, 250 isolates of $A$. solani were collected initially from the 27 fields prior to the first azoxystrobin application in a standard W-sampling pattern throughout the major growing regions of Wisconsin. A subset consisting of 33 isolates from this collection was used to determine baseline sensitivity to azoxystrobin in vitro (Table 1). Subsequent to isolate collection,

Table 1. Location and cultivar of baseline isolates of Alternaria solani collected from major potato production regions of Wisconsin in 1998

\begin{tabular}{|c|c|c|}
\hline Location $^{a}$ & $\begin{array}{c}\text { No. of } \\
\text { isolates }\end{array}$ & Cultivars \\
\hline Antigo & 4 & $\begin{array}{l}\text { Russet Burbank/ } \\
\text { Gold Rush }\end{array}$ \\
\hline Bancroft & 6 & Russet Burbank \\
\hline Coloma & 2 & Russet Burbank \\
\hline Dousman & 2 & Red Norland \\
\hline Ellis & 6 & Russet Burbank \\
\hline Endevor & 2 & Russet Burbank \\
\hline Grand Marsh & 3 & Russet Burbank \\
\hline Hancock & 4 & Russet Burbank \\
\hline Plover & 4 & Russet Burbank \\
\hline Total & 33 & $\ldots$ \\
\hline
\end{tabular}

a In Wisconsin. fields were divided into azoxystrobintreated areas and areas treated according to the growers' conventional practices (mancozeb, chlorothalonil, or triphenyltin hydroxide). A. solani collected from these pre-azoxystrobin-treated fields constituted the isolates used to determine baseline sensitivity to azoxystrobin. In 2002 and 2003, 50 potato leaves infected with $A$. solani were collected randomly in a standard W pattern from commercial growers' fields representing major production regions throughout Wisconsin. Commercial growers' fields were chosen based on differences in the history of azoxystrobin use and seasonal environmental conditions. Five of these areas were from the same general areas sampled in 1998. Potato leaves infected with $A$. solani also were received from two commercial grower fields in Minnesota in 2002 (Hope and Hollandale). The total number of $A$. solani isolates screened in fungicide sensitivity tests and Q-PCR assays was 183 and 149 in 2002 and 2003, respectively.

Leaflet lesions visually selected from similar sizes and in similar stages of sporulation were removed with a 5-mmdiameter cork borer. All leaf disks derived from a particular sampling site were placed onto water agar (WA) media amended with streptomycin and $\mathrm{CaCO}_{3}(1,000 \mathrm{ml}$ of distilled $\mathrm{H}_{2} \mathrm{O}, 15 \mathrm{~g}$ of Bacto Agar, $1.5 \mathrm{~g}$ of $\mathrm{CaCO}_{3}$, and streptomycin at $50 \mathrm{mg} / \mathrm{liter}$ ). Leaf disks were placed under fluorescent light in an incubator with a continuous photoperiod at $20^{\circ} \mathrm{C}$ for 4 days to induce sporulation for positive identification (21). After 4 days, monoconidial isolates from individual lesions were obtained by subculturing a single conidium of $A$. solani onto clarified V8 (CV8) media amended with $\mathrm{CaCO}_{3}\left(900 \mathrm{ml}\right.$ of distilled $\mathrm{H}_{2} \mathrm{O}, 100$ $\mathrm{ml}$ of $\mathrm{CV} 8,15 \mathrm{~g}$ of Bacto Agar, and $1.5 \mathrm{~g}$ of $\mathrm{CaCO}_{3}$ ). Monoconidial isolates were placed under fluorescent light in an incubator with a continuous photoperiod at $20^{\circ} \mathrm{C}$ for 10 to 14 days. Isolates were allowed to colonize and form conidia on sterilized pieces of filter paper placed on the CV8 media. Fungal material and filter paper were removed from the CV8 media, allowed to dry in a fume hood, and then stored at $-20^{\circ} \mathrm{C}$ for further analyses and to minimize any effects of further subculturing.

In vitro assay of isolate sensitivity to azoxystrobin fungicide. To determine the sensitivity of $A$. solani isolate to azoxystrobin, an in vitro plate assay was used, based on relative conidial germination on fungicide-amended media modified from previously published studies (12). Preliminary experiments were conducted to determine whether salicylhydroxamic acid (SHAM) has a lethal effect on A. solani. SHAM is a known inhibitor of the alternative oxidase (AOX) pathway that has been suggested as a possible mode of QoI resistance in vitro in other fungi (31). Sensitiv- ity of germinating conidia was tested on water agar $\left(1,000 \mathrm{ml}\right.$ of distilled $\mathrm{H}_{2} \mathrm{O}$ and $10 \mathrm{~g}$ of Bacto Agar) amended with azoxystrobin dissolved in acetone at 0.00 , $0.001,0.01,0.1,1$, and $10 \mathrm{mg} / \mathrm{liter}$ and SHAM dissolved in methanol at 100 $\mathrm{mg} / \mathrm{liter}$.

A 50- $\mu$ l aliquot from a conidial suspension of $1 \times 10^{4}$ conidia/ml (determined using a hemacytometer) was spread on the surface of azoxystrobin alone or azoxystrobin + SHAM-amended media. After incubation under continuous light for $4 \mathrm{~h}$ at $26^{\circ} \mathrm{C}$, germination was assessed for 50 conidia at each concentration (two replications). A conidium was rated as germinated if a normally developing germ tube was at least the total length of a conidium, if an appressorium formed at the tip of the germ tube, or if multiple germ tubes developed. Isolate sensitivities were expressed as relative germination (RG) (12), which is defined as the ratio of conidia germinating in the presence of azoxystrobin to those germinating in the absence of azoxystrobin $x$ 100. Isolate sensitivity expressed in $\mathrm{mg} /$ liter was determined by the effective concentration in inhibiting spore germination by $50 \%\left(\mathrm{EC}_{50}\right)$. Isolate sensitivity was determined by interpolation of the $50 \%$ intercept based on regression of the $\log$ concentration against the arcsine of RG.

Baseline isolates and isolates with reduced sensitivity were included as internal controls in sensitivity tests performed throughout these studies. Sensitivity tests were performed on batches of 20 isolates at a time for ease and efficiency and, subsequently, isolates were kept at $4^{\circ} \mathrm{C}$ after incubation to prevent further sporulation. The assay reproducibility calculations used by Wong and Wilcox (30) were applied on the internal control isolates. The assay reproducibility calculations generated the approximate limits for $95 \%$ confidence intervals.

TaqMan hybridization SNP detection assay. A Q-PCR procedure to detect a SNP was used to evaluate whether shifts in sensitivity of $A$. solani isolates to azoxystrobin were correlated with an SNP in the cytochrome $b$ gene. Where detected, the prevalence of a particular SNP was compared for local and regional differences, and in vitro sensitivity $\left(\mathrm{EC}_{50}\right)$ to azoxystrobin of $A$. solani isolates was compared between isolates that contained different SNPs in the cytochrome $b$. Genomic DNA extraction from plant (herbarium specimens) and fungal material (10- to 12-day-old cultures) was prepared using either DNeasy Plant Minikit (Qiagen, Valencia, CA) or Bio101 Fast DNA Kit (Qbiogene, Carlsbad, CA) according to the manufacturers' protocols. Genomic DNA, conidia, or mycelia was stored on dry ice and sent to Syngenta Vero Beach, FL or Jealott's Hill, UK for SNP detection assays.

Primers and fluorescent-labeled minor groove-binding probes were designed for 
the detection of the four SNPs responsible for the G143A (GCT to GGT) and F129L (TTC to TTA, CTC and TTG) amino acid substitutions in A. solani (International Patent Publication No.WO02081742; Table 2). TaqMan hybridization amplifications were performed in a total volume of $25 \mu \mathrm{l}$ containing $5 \mu \mathrm{l}$ of template DNA, $2 \times$ TaqMan mastermix (Applied Biosystems Inc., Foster City, CA), $18 \mu \mathrm{M}$ forward and reverse primer, and $2 \mu \mathrm{M}$ wild-type and mutant probe. Reactions were performed using the following cycling profile: $50^{\circ} \mathrm{C}$ for $2 \mathrm{~min}, 95^{\circ} \mathrm{C}$ for $10 \mathrm{~min}, 35$ cycles of $92^{\circ} \mathrm{C}$ for $15 \mathrm{~s}$, and $60^{\circ} \mathrm{C}$ for $1 \mathrm{~min}$. Data collection was carried out during the $60^{\circ} \mathrm{C}$ step with 5-carboxy-X-rhodamine (ROX) as the reference standard on an ABI prism 7700 or $7900 \mathrm{HT}$ real-time PCR instrument (Applied Biosystems Inc.).

Data analysis. Because arithmetic $\mathrm{EC}_{50}$ values from the sensitivity tests were found not to follow a normal distribution, mean $\log \mathrm{EC}_{50}$ values were compared using one-way analysis of variance and Fisher's protected least significant difference (LSD). Arithmetic $\mathrm{EC}_{50}$ values were reported in results as appropriate. Frequencies of recovery of each of the mutant types were compared using a $\chi^{2}$ test to assess for potential differences between locations and collection years. Mean $\mathrm{EC}_{50}$ values of individual SNP mutants were compared using one-way analysis of variance and Fisher's protected LSD procedure. All statistical analyses were performed with Minitab Xtra Power (v.10.5; Minitab Inc., State College, PA) or SAS (v.8.0; SAS Institute Inc., Cary, NC). Realtime PCR assay results were analyzed using SDS software (v.1.7; Applied Biosystems Inc.).

\section{RESULTS}

In vitro assay of isolate sensitivity to QoI fungicides: assay reproducibility. There was a high reproducibility in the $\mathrm{EC}_{50}$ values between replicate samples in our azoxystrobin sensitivity assay. For the nine isolates examined individually, means of relative germination ranged from 0.01 to 0.02 , with coefficients of variation ranging from 0.10 to 0.25 (Table 3 ). The overall mean sensitivity to azoxystrobin $\left(\mathrm{EC}_{50}\right.$ value) of the nine baseline isolates of $A$. solani was $0.015 \mathrm{mg} / \mathrm{liter}$, with a coefficient of variation of 0.17 .

Baseline distributions of $A$. solani sensitivities to azoxystrobin. No lethal effects from SHAM were observed using 23 baseline or 25 nonbaseline isolates of $A$. solani that were tested in vitro with azoxystrobin and azoxystrobin + SHAM. Therefore, all subsequent in vitro sensitivity tests were performed with azoxystrobin + SHAM. In vitro sensitivity, expressed as $\mathrm{EC}_{50}$ values representing baseline $A$. solani isolates, ranged from 0.012 to 0.997 $\mathrm{mg} / \mathrm{liter}$ to azoxystrobin alone (data not shown). Baseline isolate sensitivity in the presence of SHAM ranged from 0.01 to $0.07 \mathrm{mg} /$ liter for azoxystrobin (Table 4). In vitro sensitivity of baseline isolates of $A$. solani was widely distributed, with a mean sensitivity of $0.18 \mathrm{mg} / \mathrm{liter}$ (standard deviation $[\mathrm{SD}]=0.09$ ) for azoxystrobin alone (data not shown). Mean sensitivity $\left(\mathrm{EC}_{50}\right)$ in the presence of azoxystrobin + SHAM was significantly lower, $0.03 \mathrm{mg} /$ liter (SD $=0.01)$, compared with azoxystrobin alone, and was narrowly distributed among baseline isolates (Tables 3 and 4).

Sensitivity and distribution of $A$. solani populations exposed to azoxystrobin. Mean sensitivity in vitro of isolates collected during statewide monitoring in 2002 and 2003 was not significantly different between years $(P=0.0915)$; however, both 2002 and 2003 mean $\mathrm{EC}_{50}$ values were significantly higher than the baseline $A$. solani isolates collected in $1998\left(P<0.0001\right.$; Table 5). Mean $\mathrm{EC}_{50}$ $(\mathrm{mg} / \mathrm{liter})$ values increased by more than 20-fold between the 1998 isolates baseline and 2003 isolates (Table 5). Within years, there was no significantly difference in mean $\mathrm{EC}_{50}$ values among locations in Wisconsin (2002: $P=0.0928 ;$ 2003: $P=$ 0.0987). Results from the in vitro assay indicated that, in 2002, there was a significant difference between Wisconsin and one site near Hope, $\mathrm{MN}(P=0.0011)$.

TaqMan hybridization SNP detection assay: molecular analysis of $A$. solani cytochrome $\boldsymbol{b}$. No mutations were detected in a subsample of baseline isolates recovered in 1998 and all isolates were classified wild type at amino acid positions 129 (F; codon TTC) and $143(\mathrm{G}$; codon GGT) (Table 4). All of the A. solani isolates collected in 2002 and 2003 were characterized as wild type at position 143 , whereas all three SNPs responsible for the F129L substitution (TTA, CTC, and TTG) were detected in these samples (Table 4).

Frequency and statewide distribution of $A$. solani SNP mutants. The majority (96\%) of the 2002 isolates contained an F129L-inducing SNP. All of the isolates collected in 2003 were F129L mutants and no wild-type isolates (TTC) were detected. Wild-type isolates of A. solani were recovered at a higher frequency in Hope, $\mathrm{MN}$ in 2002 (Table 4) than in all other locations. The results from the SNP detection assays indicated that there was a significant spatial and temporal difference in the frequency of F129L SNPs mutants recovered

Table 2. Oligonucleotide and fluorescent probe sequences for real-time polymerase chain reaction assay, sequences from Syngenta International Patent WO02081742a

\begin{tabular}{ll}
\hline Primers, probes & \multicolumn{1}{c}{ Sequence $\left(\mathbf{5}^{\prime}\right.$ to $\left.\mathbf{3}^{\prime}\right)$} \\
\hline 129 Forward primer & GAACTATTGGTACTGTTATCTTTATCTTAATGATG \\
129 Reverse primer & AAACCATTTTGGGCTATGTTGG \\
143 Forward primer & GTATGTTCTTCCTTATGGGCAAATG \\
143 Reverse primer & CTCTACTTTGTTTATGTTATTTAACCAAGAATG \\
129 WT probe & [VIC] CTACAGCTTTCCTGGGTT \\
129 MUT1 probe & [FAM] CTACAGCTCTCCTGGGT \\
129 MUT2 probe & [FAM] CTACAGCTTTACTGGGTTA \\
129 MUT3 probe & [FAM] CTACAGCTTTGCTGGGT \\
143 WT probe & [VIC] TCTTTATGAGGTAAATTT \\
143 MUT probe & {$[$ FAM] TCTTTATGAGCTAAATTT } \\
\hline
\end{tabular}

a Underlined codon corresponds to single-nucleotide polymorphism responsible for F129L substitution.

Table 3. Reproducibility of effective concentration in inhibiting spore germination by $50 \%\left(\mathrm{EC}_{50}\right.$ values) determined against nine of the baseline isolates of Alternaria solani employing a relative germination assay

\begin{tabular}{lccc}
\hline & \multicolumn{3}{c}{$\mathbf{E C}_{\mathbf{5 0}}(\mathbf{m g} / \mathbf{l i t e r}) \mathbf{R G}^{\mathbf{a}}$} \\
\cline { 2 - 4 } Isolate & Mean $^{\mathbf{b}}$ & $\mathbf{9 5 \%} \mathbf{C I}$ & $\mathbf{C V}$ \\
\hline $98-24$ & 0.010 & 0.010 to 0.016 & 0.10 \\
$98-25$ & 0.017 & 0.017 to 0.033 & 0.16 \\
$98-47$ & 0.014 & 0.014 to 0.024 & 0.13 \\
$98-74$ & 0.016 & 0.016 to 0.034 & 0.18 \\
$98-84$ & 0.012 & 0.011 to 0.021 & 0.14 \\
$98-100$ & 0.013 & 0.012 to 0.026 & 0.16 \\
$98-120$ & 0.020 & 0.019 to 0.029 & 0.10 \\
$98-217$ & 0.014 & 0.013 to 0.037 & 0.23 \\
$98-223$ & 0.017 & 0.017 to 0.048 & 0.25 \\
Mean & 0.015 & 0.014 to 0.030 & 0.17 \\
\hline
\end{tabular}

${ }^{\mathrm{a}} \mathrm{EC}_{50}$ values determined for relative germination $(\mathrm{RG})$ was assessed for two replications of 50 conidia at each concentration $(0.00,0.001,0.01,0.1,1$, and $10 \mathrm{mg} / \mathrm{liter})$ after incubation under continuous light for $4 \mathrm{~h}$ at 20 or $26^{\circ} \mathrm{C}$ with a conidial suspension of $1 \times 10^{4}$ conidia/ml spread on the surface of azoxystrobin + salicylhydroxamic acid-amended media.

${ }^{\mathrm{b}}$ Mean $=$ mean $\mathrm{EC}_{50}$ value based on four repeated assays; $95 \%$ confidence interval $(\mathrm{CI})$ based upon log-transformed $\mathrm{EC}_{50}$ values, values expressed as the antilog of the calculated interval; $\mathrm{CV}=$ the coefficient of variation, expressed as an absolute value (standard error of the mean of $\log \mathrm{EC}_{50}$ values)/(mean of $\log \mathrm{EC}_{50}$ values). 
in Wisconsin $\left(\chi^{2}=40.32 ; P=0.0197\right)$. There also was a significant difference in frequency of SNP types detected in 2002 between five fields in Wisconsin and two fields in Minnesota $\left(\chi^{2}=112.21 ; P<\right.$ $0.0001)$. There was a significant difference in the frequency of mutant types detected between the two locations in Minnesota in $2002(P=0.0006)$. The most common mutant codon found in Wisconsin was TTA (77\%) followed by CTC (19\%) and TTG (2\%). The most common mutant codon recovered in Minnesota was CTC (56\%) followed by TTA $(23 \%)$ and TTG (10\%).

Sensitivity distribution of $A$. solani SNP mutants to azoxystrobin. Mean in vitro sensitivities to azoxystrobin $\left(\mathrm{EC}_{50}\right.$ values) among isolates containing the different F129L SNPs were not significantly different from one another, but were significantly different from the wild-type isolates (LSD, $P=0.0011$ ) (Table 6). The mean sensitivity to azoxystrobin of the TTA, CTC, and TTG mutants and the TTC wild type was $0.63,0.53,0.74$, and 0.09 $\mathrm{mg} /$ liter, respectively (Table 6).

\section{DISCUSSION}

Isolates of $A$. solani recovered from commercial potato fields in Wisconsin had reduced in vitro sensitivity to azoxystrobin along with amino acid substitution in the cytochrome $b$ gene (Tables 3 and 4 ). The reduced sensitivity was associated consistently with site-specific amino acid substitutions in only one gene, cytochrome $b$, and was a result of three different mutations restricted to position 129. Results indicate a more than 20 -fold reduction in sensitivity in vitro to azoxystrobin $\left(\mathrm{EC}_{50}\right.$ values) between 1998 and 2002-03 (Tables 3 and 4).
The in vitro assay detected and quantified the proportion of isolates of A. solani in Wisconsin with reduced sensitivity to azoxystrobin. These results are similar to other studies for detecting QoI resistance in fungal plant pathogen populations (3$5,9,11,13,14,29)$. Data suggest an approximate 10 -fold directional selection in A. solani populations toward reduced sensitivity to the QoI fungicide azoxystrobin (Tables 3 and 4). That value is similar but somewhat higher than previous studies, which have observed an approximately fivefold difference in sensitivity between the lowest and highest $\mathrm{EC}_{50}$ values for azoxystrobin $(13,14,31)$. Contrary to previous studies in other plant pathogens, this study correlated reduced sensitivity to azoxystrobin to three different SNPs at position 129 of cytochrome $b$ in A. solani. Moreover, this study determined the frequency and distribution of these different SNP types at the population level in a major potato production area with a history of QoI fungicide use.

Q-PCR assays performed on the 1998 baseline $A$. solani isolates indicated that all baseline isolates exhibited the wild-type genotype, with no amino acid substitutions at positions 129 and 143 (Table 4). None of the isolates collected in 2002 or 2003 were found to carry mutations at the base pair position 143 in the cytochrome $b$ gene, including isolates that demonstrated elevated $\mathrm{EC}_{50}$ values in vitro (data not shown). In contrast, all three potential mutations at position 129 were detected in 2002 and 2003 at various frequencies (Table 4). Although previous studies reported the effects of the F129L on mitochondrial respiration $(13,14)$, this study is the first to report differences in frequency and codon usage resulting in the F129L substitution in fungi at the population level. Furthermore, this study is the first to use molecular probes in order to detect both mutations that previously have been shown to be associated with reduced-sensitivity and resistance to azoxystrobin, positions 129 and 143, respectively, of cytochrome $b$.

Mean sensitivity, based on in vitro spore germination, consistently was associated with an elevated $\mathrm{EC}_{50}$ value and the presence of point mutations of the codon at position 129 in the cytochrome $b$ gene of A. solani. The minimum sensitivity de-

Table 5. Comparison of mean effective concentration in inhibiting spore germination by $50 \%\left(\mathrm{EC}_{50}\right)$ values to azoxystrobin + salicylhydroxamic acid for isolates of Alternaria solani from Wisconsin

\begin{tabular}{lccccc}
\hline Year & $\begin{array}{c}\text { No. of } \\
\text { isolates }^{\mathbf{a}}\end{array}$ & $\begin{array}{c}\text { Mean EC }_{\mathbf{5 0}} \\
\text { (mg/liter) }^{\mathbf{b}}\end{array}$ & $\begin{array}{c}\text { Standard } \\
\text { deviation }^{-}\end{array}$ & Minimum & Maximum \\
\hline 1998 & 30 & $0.03^{\mathrm{c}}$ & 0.01 & 0.01 & 0.07 \\
2002 & 105 & 0.61 & 0.38 & 0.05 & 1.98 \\
2003 & 48 & 0.83 & 0.98 & 0.13 & 4.6 \\
LSD & $\ldots$ & 0.23 & $\ldots$ & $\ldots$ & $\ldots$ \\
Total & 183 & $\ldots$ & $\ldots$ & $\ldots$ & $\ldots$ \\
\hline
\end{tabular}

a Subsample of isolates were screened in vitro.

b $\mathrm{EC}_{50}$ values expressed as arithmetic mean.

c Indicates a significant difference in mean $\mathrm{EC}_{50}$ using Fisher's protected least significant difference (LSD) test $(P<0.0001)$.

Table 4. Location, spray history, collection date, cultivar, mean effective concentration in inhibiting spore germination by $50 \%$ (EC 50 ), and frequency of single-nucleotide polymorphisms (SNPs) causing the amino acid substitution F129L recovered from statewide sampling from eight fields in Wisconsin from 1998, 2002, and 2003 and two from Minnesota in 2002

\begin{tabular}{|c|c|c|c|c|c|c|c|c|c|}
\hline \multirow[b]{3}{*}{ Location } & \multirow[b]{3}{*}{ QoI $^{b}$} & \multirow[b]{3}{*}{ Year $^{\mathrm{c}}$} & \multirow[b]{3}{*}{ Cultivars $^{d}$} & \multirow[b]{3}{*}{ Number $^{\mathrm{e}}$} & \multirow[b]{3}{*}{$\mathrm{EC}_{50}\left(\mathrm{mg} /\right.$ liter $^{\mathrm{f}}$} & \multicolumn{4}{|c|}{ No. of samples (\%) } \\
\hline & & & & & & \multirow{2}{*}{$\begin{array}{c}\text { Wild type } \\
\text { TTC }\end{array}$} & \multicolumn{3}{|c|}{ Mutant type } \\
\hline & & & & & & & TTA & CTC & TTG \\
\hline Wisconsin & $\mathrm{B}, 0$ & 1998 & Various & 33 & $0.03,0.01-0.07$ & $20(100)$ & $0(0)$ & $0(0)$ & $0(0)$ \\
\hline Antigo, WI & 0 & 2002 & Snowden & 22 & $0.64,0.05-1.41$ & $2(9)$ & $15(65)$ & $6(26)$ & $0(0)$ \\
\hline Cameron, WI & 4 & 2002 & Russet Burbank & 24 & $0.45,0.22-1.08$ & $0(0)$ & $14(64)$ & $8(36)$ & $0(0)$ \\
\hline Coloma, WI & 3 & 2002 & Russet Burbank & 58 & $0.55,0.19-1.12$ & $0(0)$ & $51(91)$ & $4(7)$ & $1(2)$ \\
\hline Dousman, WI & 3 & 2002 & Red Norland & 39 & $0.89,0.28-1.55$ & $1(4)$ & $18(72)$ & $6(24)$ & $0(0)$ \\
\hline Plover, WI & 2 & 2002 & RB-GR & 49 & $0.67,0.24-1.98$ & $0(0)$ & $40(82)$ & $7(14)$ & $2(4)$ \\
\hline Grand Marsh, WI & 4 & 2003 & Russet Burbank & 23 & $0.48,0.22-1.04$ & $0(0)$ & $11(85)$ & $2(15)$ & $0(0)$ \\
\hline Plover, WI & 2 & 2003 & Russet Burbank & 25 & $1.22,0.23-4.60$ & $0(0)$ & 9 (64) & $3(21)$ & $2(15)$ \\
\hline Sand Creek, WI & 3 & 2003 & Russet Burbank & 17 & NA & $0(0)$ & $13(72)$ & $5(28)$ & $0(0)$ \\
\hline Spring Green, WI & 5 & 2003 & Russet Norkotah & 28 & $0.73,0.13-3.45$ & $0(0)$ & $5(71)$ & $2(29)$ & $0(0)$ \\
\hline Hollandale, MN & 4 & 2002 & Cascade & 54 & $0.64,0.17-1.72$ & $0(0)$ & $10(22)$ & $30(65)$ & $6(13)$ \\
\hline Hope, MN & 2 & 2002 & Cascade & 22 & $0.42,0.06-2.36$ & $6(29)$ & $6(29)$ & $8(38)$ & $1(4)$ \\
\hline
\end{tabular}

a Subsample of isolates that resulted in positive amplification in TaqMan hybridization SNP detection assay. TTC is wild type at position 129 in the cytochrome b in Alternaria solani and TTA, CTC, and TTG are the SNPs at position 129 in the cytochrome $b$ gene conferring resistance to azoxystrobin. NA = not available.

b Number of quinone outside inhibitor (QoI) applications per year; B = baseline.

c Collection year.

${ }^{\mathrm{d}}$ RB-GR = Russet Burbank and Gold Rush.

e Number of $A$. solani isolates screened using in vitro sensitivity assay.

${ }^{\mathrm{f}} \mathrm{EC}_{50}$ values expressed as arithmetic mean, followed by minimum-maximum. 
tected in the 2002 populations was within the range of baseline isolates, indicating that there were some wild-type isolates recovered from statewide monitoring. However, in 2003, there were no isolates recovered from statewide monitoring with $\mathrm{EC}_{50}$ values within the range of baseline isolates. This possibly may be due largely to the influx and saturation of the populations of $A$. solani mutants with reduced sensitivity to azoxystrobin. Moreover, the locations where wild-type isolates were recovered in 2002 (Antigo and Dousman, WI) were not sampled in 2003. Our molecular results are consistent with this because the wild-type was detected at a lower frequency in 2002 from Wisconsin (4\% of isolates) compared with SNP mutants, and no wild-type isolates were recovered in 2003. Coupled with concurrent experimental field efficacy studies over the previous seven seasons (1997-2003) showing that azoxystrobin efficacy has declined (2328 ), our results suggest that a directional selection favoring a reduced-sensitivity $A$. solani phenotype has occurred at the population level in Wisconsin subsequent to the commercial release of Quadris. There was, however, spatial and temporal differences in the frequency of mutant types (TTA, CTC, and TTG) detected among locations in Wisconsin. These genotypic differences suggest that the population of $A$. solani and this particular trait has a slightly different distribution pattern throughout the primary potato production regions in Wisconsin.

There was a difference in genotypic variability of isolates recovered from Wisconsin and Minnesota (Table 4). Quantitative PCR results further confirmed data from in vitro sensitivity ( $\mathrm{EC}_{50}$ values) tests $\mathrm{MN}$ ) was different from locations in Wisconsin and a second location in Minnesota (Hollandale, MN). This was due in large part to a high frequency of isolates at the Hope, $\mathrm{MN}$ site with $\mathrm{EC}_{50}$ values similar to baseline isolates collected in Wisconsin prior to commercial use of QoIs. This trend also was reflected in a higher number of wild-type isolates detected in the SNP that one location in Minnesota (Hope,

assay. The locations in Minnesota were approximately $50 \mathrm{~km}$ apart and both were planted with the potato $\mathrm{cv}$. Cascade, which is highly susceptible to early blight (6). Both locations were described as having elevated disease pressure by crop consultants and leaf samples from both exhibited a similar amount of highly diseased leaf area; however, product use differed in total number of applications of azoxystrobin during the growing season (two and four applications of azoxystrobin at Hope and Hollandale, MN, respectively). Future product use strategies focused on fungicide resistance management may have to be adapted to local production practices, taking into account environmental, cultural, and varietal factors.

There was no difference in population mean sensitivity or the frequency of mutant type detected among locations and years in Wisconsin subsequent to azoxystrobin use (2002 and 2003). Early blight control, however, appeared not to be related to the frequency and pattern of azoxystrobin use. The reduction in population sensitivity was observed regardless of history of azoxystrobin use (average of zero to five applications per season), as was the case in 2002, where mean sensitivity was lower in isolates collected from Plover, WI (two applications of Quadris) than isolates collected from Cameron, WI (four applications of Quadris) (Table 4). Again, this may be due in large part to the influx and saturation of $A$. solani mutants with reduced sensitivity to azoxystrobin. The displacement of wild-type populations of A. solani statewide likely may be the result of four factors: (i) spore dispersal occurring within and among fields due to prevailing weather and wind, which are primarily responsible for long-distance spore dispersal; (ii) seedborne inoculum from early blight-infected seed tubers; (iii) inoculum from residual plant debris from previous growing seasons; or (iv) inoculum produced on other Solanaceous hosts.

The importance of decreasing pesticide inputs, coupled with the use of effective reduced-risk chemistries, such as azox-

Table 6. Comparison of the impact of different single-nucleotide polymorphism (SNP) types causing the amino acid substitution F129L on mean effective concentration in inhibiting spore germination by $50 \%\left(\mathrm{EC}_{50}\right)$ values to azoxystrobin + salicylhydroxamic acid in isolates of Alternaria solani collected in 2002

\begin{tabular}{cccccc}
\hline SNP type $^{\mathbf{a}}$ & $\begin{array}{c}\text { No. of } \\
\text { isolates }\end{array}$ & $\begin{array}{c}\text { Mean EC }_{\mathbf{5 0}} \\
(\mathbf{m g} / \text { /iter) }\end{array}$
\end{tabular}

a TTC is wild type at position 129 in the cytochrome b in Alternaria solani and TTA, CTC, and TTG are the SNPs at position 129 in the cytochrome $b$ gene conferring resistance to azoxystrobin.

${ }^{\mathrm{b}} \mathrm{EC}_{50}$ values expressed as arithmetic mean.

${ }^{\mathrm{c}}$ Indicates a significant difference in mean $\mathrm{EC}_{50}$ using Fisher's protected least significant difference test $(P=0.0011)$. ystrobin, has become important for growers of commercial potato production, particularly in regions where environmental factors such as temperature, relative humidity, and so on favor disease development. Moreover, growers have observed a boost in tuber yield when azoxystrobin was included in their management program (W. R. Stevenson, unpublished). Effective disease control usually was achieved when growers strictly adhered to the current Quadris label recommendations for the use of QoI fungicides. Therefore, if growers decide to continue using azoxystrobin it is recommended to (i) limit the number of QoI applications to one-third of the total number of sprays during a season; (ii) apply QoI fungicides early in the growing season alternated (no consecutive applications), tank mixed, or, when available, as prepack mixes with compounds of different chemistries; and (iii) never use QoI fungicides in a curative manner. Although there appears to be a progressive decline in efficacy of fungicide application programs alternating Quadris and Bravo (chlorothalonil) for early blight control in field experiments, there have been no reports of complete product failure from commercial potato growers in Wisconsin.

\section{ACKNOWLEDGMENTS}

This work was supported in part by Syngenta Crop Protection Inc., the Wisconsin Potato and Vegetable Growers Association, and the University of Wisconsin-Madison, College of Agricultural and Life Sciences. We thank P. G. Kennedy for critical review of this manuscript.

\section{LITERATURE CITED}

1. Avila-Cruz, A., Olaya, G., and Köller, W. 2003. Characterization of Colletotrichum graminicola isolates resistant to strobilurinrelated QoI fungicides. Plant Dis. 87(12):14261432.

2. Bartlett, D. W., Clough, J. M., Godwin, J. R., Hall, A. A., Hamer, M., and Parr-Dobrzanski, B. 2002. The strobilurin fungicides. Pest Manage. Sci. 58(7):649-662.

3. Chin, K. M., Chavaillaz, D., Kaesbohrer, M. Staub, T., and Felsenstein, F. G. 2001. Characterizing resistance risk of Erysiphe graminis $\mathrm{f}$. sp. tritici to strobilurins. Crop Prot. 20(2):8796.

4. Chin, K. M., Felsenstein, F. G., and Gisi, U. 1998. Stabilizing selection of Erysiphe graminis f. sp. tritici populations for sensitivity to sterol biosynthesis inhibitors. Paper read at Proc. 7th Int. Congr. Plant Pathol. Edinburgh.

5. Heaney, S. P., Davies, S. A., Bradley, S. S., and Oakhill, J. S. 1997. Determination of baseline sensitivities of European populations of Plasmopara viticola and Uncinula necator to the new strobilurin fungicide, azoxystrobin. Paper read at Resistance '97 Integrated Approach to Combating Resistance, Harpenden, UK.

6. Hoyman, W. G. 1970. Cascade: a new variety for the processing of frozen french fries. Am. Pot. J. 47:261-263.

7. Ishii, H., Fraaije, B. A., Sugiyama, T., Noguchi, K., Nishimura, K., Takeda, T., Amano, T., and Hollomon, D. W. 2001. Occurrence and molecular characterization of strobilurin resistance in cucumber powdery mildew and downy mildew. Phytopathology 91(12):1166-1171.

8. Kim, Y. S., Dixon, E. W., Vincelli, P., and Farman, M. L. 2003. Field resistance to strobilurin (QoI) fungicides in Pyricularia grisea 
caused by mutations in the mitochondrial cytochrome $b$ gene. Phytopathology 93(7):891900 .

9. Küng Färber, R., Chin, K. M., and Leadbitter, N. 2002. Sensitivity of Venturia inaequalis to trifloxystrobin. Pest Manage. Sci. 58(3):261267.

10. Ma, Z., Felts, D., and Michailides, T. J. 2003. Resistance to azoxystrobin in Alternaria isolates from pistachio in California. Pestic. Biochem. Physiol. 77(2):66-74.

11. Olaya, G., Cleere, S., Stanger, C., Burbidge, J., Hall, A., and Windass, J. 2003. A novel potential target site QoI fungicide resistance mechanism in Pythium aphanidermatum. (Abstr.) Phytopathology 93:S67.

12. Olaya, G., and Köller, W. 1999. Baseline sensitivities of Venturia inaequalis populations to the strobilurin fungicide kresoxim-methyl. Plant Dis. 83:274-278.

13. Pasche, J. S., Piche, L. M., and Gudmestad, N. C. 2005. Effect of the F129L mutation in $\mathrm{Al}$ ternaria solani on fungicides affecting mitochondrial respiration. Plant Dis. 89:269-278.

14. Pasche, J. S., Wharam, C. M., and Gudmestad, N. C. 2004. Shift in sensitivity of Alternaria solani in response to QoI fungicides. Plant Dis. 88(2): 181-187.

15. Pscheidt, J. W. 1986. Early Blight of Potato and Tomato: A Literature Review. Univ. Wis. Ext. Coop. Ext. Serv. 3376. Research Division of the College of Agriculture and Life Sciences University of Wisconsin-Madison.
16. Reschke, M. 1999. Strobis in Gefahr. Dtsch. Landwirtsch. Ges. Mitt. 1:51.

17. Rosenzweig, N., and Stevenson, W. R. 2002. Efficacy of strobilurin fungicides to control potato early blight in Wisconsin. (Abstr.) Phytopathology 92:S71.

18. Rosenzweig, N., and Stevenson, W. R. 2003. Sensitivity of Alternaria solani to azoxystrobin. (Abstr.) Phytopathology 93:S75.

19. Rosenzweig, N., and Stevenson, W. R. 2004. Tracking changes in sensitivity of Alternaria solani to azoxystrobin in WI. (Abstr.) Phytopathology 94:S161.

20. Rotem, J. 1994. The Genus Alternaria: Biology, Epidemiology, and Pathogenicity. American Phytopathological Society Press, St. Paul, MN.

21. Shahin, E. A., and Shepard, J. F. 1979. An efficient technique for inducing profuse sporulation of Alternaria species. Phytopathology 69:618-620.

22. Sierotzki, H., Wullschleger, J., and Gisi, U. 2000. Point mutation in cytochrome b gene conferring resistance to strobilurin fungicides in Erysiphe graminis f. sp. tritici field isolates. Pestic. Biochem. Physiol. 68(2):107-112.

23. Steinfeld, U., Sierotzki, H., Parisi, S., and Gisis, U. 2003. Comparison of resistance mechanisms to strobilurin fungicides in Venturia inaequalis. In: Modern Fungicides and Antifungal Compounds III. H. W. Dehne, U. Gisi, K. H. Kuck, R. P. E., and H. Lyr, eds. AgroConcept, Bonn, Germany.
24. Stevenson, W. R., and James, R. V. 2000 Evaluation of fungicides to control potato early blight and late blight, 1999. Fungic. Nematicide Tests 55:228.

25. Stevenson, W. R., and James, R. V. 2001 Evaluation of fungicides to control potato early blight and late blight, 2000. Fungic. Nematicide Tests 56:V53.

26. Stevenson, W. R., and James, R. V. 2002 Evaluation of fungicides to control potato early blight and late blight 2001. Fungic. Nematicide Tests 57:V072:1-3.

27. Stevenson, W. R., and James, R. V. 2003. Evaluation of fungicides to control early blight and late blight of potato, Hancock, 2002. Fungic. Nematicide Tests 58:V046:1-3.

28. Stevenson, W. R., and James, R. V. 2004 Evaluation of fungicides to control early blight of potato, Hancock, WI 2003. Fungic. Nematicide Tests 59:V040:1-2.

29. Walker, A. S. L., and Cooke, L. R. 1990. The survival of Phytophthora infestans in potato tubers: the influence of phenylamide resistance. Brighton Crop Prot. Conf. 1109-1114.

30. Wong, F. P., and Wilcox, W. F. 2000. Distribution of baseline sensitivities to azoxystrobin among isolates of Plasmopara viticola. Plant Dis. 84:275-281.

31. Ziogas, B. N., Baldwin, B. C., and Young, J. E. 1997. Alternative respiration: a biochemical mechanism of resistance to azoxystrobin (ICIA 5504) in Septoria tritici. Pestic. Sci. 50(1):2834 